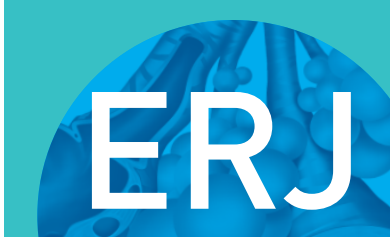

open research

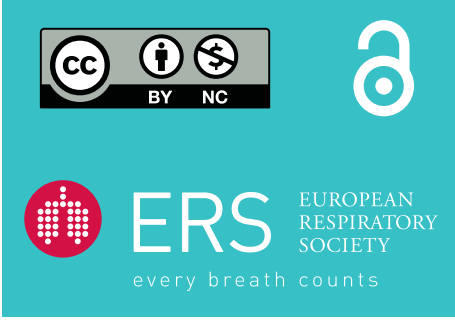

\section{Soft cervical collar in obstructive sleep apnoea: a pilot study}

\section{To the Editor:}

A soft cervical collar is a simple-to-use, noninvasive, nonintrusive, cheap and comfortable external support that can be used after cervical surgery or injuries such as whiplash $[1,2]$. It limits cervical and head movements such as antero-posterior flexion/extension and backward motion of the mandible [3, 4]. In obstructive sleep apnoea (OSA), upper airway obstruction can be caused by anterior flexion of the head or by backward seesaw motion of the mandible and the tongue in supine position [3,5-7]. Prior to a randomised controlled trial (RCT) using such a support to treat OSA, we assessed in a pilot study 1) night tolerance of the soft cervical collar in patients with OSA; 2) alteration of pharyngeal patency according to polygraphy data with this support in OSA; and 3) trial population size for conclusive results.

Since no publication had reported the effects of a soft cervical support in OSA, our study was conducted as a pilot study. Among 77 consecutive new participants referred for suspicion of sleep apnoea, we selected those in whom severe OSA was confirmed (apnoea-hypopnoea index (AHI) $\geqslant 30$ events $\cdot \mathrm{h}^{-1}$ ) with a baseline nocturnal cardiorespiratory polygraphy (Embletta PDS system, Medcare Flaga, Reykjavik, Iceland; Proxy connector X10 or X30). We considered severe OSA in order to allow more flagrant effects of the cervical support. We recruited 24 patients via a screening phase, which took place over 52 weeks. Cervical collars were tried on to determine the correct model for each patient, six different sizes in height and length being available (Medisport, Ruaudin, France). The model was selected when a significant limitation of head motion was obtained and with comfort for the patient (see discussion). Three patients had too large a neck to wear one of the collar models available for the study. It thus became apparent that certain anatomic characteristics could be an obstacle to the use of such a support. Another patient finally refused to wear the collar while polygraphy was being installed for the second recording due to a choking sensation. Therefore, 20 patients included in the study, randomly assigned to wear either a soft cervical collar at night for the intervention group $(n=10)$ or no support for the control group $(n=10)$, underwent a second nocturnal polygraphy soon after the baseline recording. For this second nocturnal polygraphy the patients assigned to the intervention group were shown how to install the cervical collar at home and wear it from the moment they turned off the lights until they woke up in the morning. After getting up in the morning, those patients filled out a questionnaire on collar tolerance throughout the night with questions as follows and answering "yes, no, don't know" to each item: "Did the collar disturb your sleep? Did you feel obliged to remove the collar? Did you experience any sensation of choking? Did you suffer from a sensation of heat due to the collar? Did you have any difficulty in swallowing? Would you agree to wear this support night after night?" At study discharge continuous positive airway pressure (CPAP) therapy was proposed to all study patients. Patients gave their informed written consent to participate in the study.

All nocturnal cardiorespiratory recordings took place at home following installation of the sensors and the polygraph onto the patient early in the evening in our laboratory. The polygraphy devices were programmed according to patients' information to record the signals from lights out once in bed in the evening to final awakening in the morning. All recordings were visually and anonymously scored by two experienced sleep specialists using standard criteria from the American Academy of Sleep Medicine 2016 guidelines [8].

@ERSpublications

In severe obstructive sleep apnoea, a soft cervical collar was well tolerated at night in 10 patients with no changes in polygraphy results. With the same design, a randomised controlled trial would need 246 inclusions for conclusive results. https://bit.ly/2KiU3j1

Cite this article as: Bordier P, Lataste A, Orazio S, et al. Soft cervical collar in obstructive sleep apnoea: a pilot study. ERJ Open Res 2021; 7: 00431-2020 [https://doi.org/10.1183/23120541.004312020].

Copyright $\odot$ ERS 2021. This article is open access and distributed under the terms of the Creative Commons Attribution NonCommercial Licence 4.0. 
Analyses were performed using $\mathrm{R}$ software environment, with Sidak adjustment and a p-value $<0.002$ was considered statistically significant [9]. To control variability of the measurements due to the small sample size we standardised the data changes between both recordings, obtaining standardised evolution indicators as previously described [10], a p-value $<0.01$ being then considered statistically significant. Required trial population size was calculated using Cohen's $d$ method with functions contained in the pwr package from R software [11].

Overall, 14 men and 6 women aged $53.3 \pm 2.7,34.0 \pm 0.3 \mathrm{~kg} \cdot \mathrm{m}^{-2}$, were studied. There were no significant differences in the standard clinical characteristics between the control and intervention groups. The questionnaire on collar tolerance at night demonstrated no severe inconvenience except in one patient who experienced a choking sensation, resulting in collar removal during night recording. Nevertheless, the collar was well tolerated by a majority of patients with a sensation of heat as the most frequent discomfort. Five patients said that they would have agreed to wear it more nights, two said no and three said that they do not know. Table 1 presents the comparison between the baseline and second nocturnal recordings in the control group versus the intervention group. No data changes between the two recordings were significantly different between both groups. Supine position was reported over $99.5 \%$ of recording time in all study recordings. Recording time in dorsal decubitus during the baseline and second recordings represented, respectively, $32.7 \% \pm 6.1 \%$ and $29.1 \% \pm 4.8 \%$ in the control group and, respectively, $41.3 \% \pm 9.1 \%$ and $56.1 \% \pm 9.7 \%$ in the intervention group. This trend to more time in dorsal decubitus with the collar was not associated with an increase in AHI. Dorsal AHI during the baseline and second recordings was, respectively, $73.2 \pm 7.9 \cdot \mathrm{h}^{-1}$ and $62.8 \pm 10.6 \cdot \mathrm{h}^{-1}$ in the control group and, respectively, $86.3 \pm 6.8 \cdot \mathrm{h}^{-1}$ and

TABLE 1 Baseline and second-night polygraphy variables in control and intervention groups

\begin{tabular}{|c|c|c|c|c|c|c|}
\hline & \multicolumn{3}{|c|}{ Control group $(n=10)$} & \multicolumn{3}{|c|}{ Intervention group $(n=10)$} \\
\hline & Baseline & $\begin{array}{l}\text { Second } \\
\text { night }\end{array}$ & p-value & Baseline & $\begin{array}{l}\text { Second } \\
\text { night }\end{array}$ & p-value \\
\hline Recording time min & $444 \pm 11$ & $450 \pm 12$ & 0.5 & $434 \pm 14$ & $434 \pm 14$ & 0.95 \\
\hline Median & 435 & 443 & & 429 & 431 & \\
\hline Interquartile range & $414-461$ & $416-483$ & & $414-461$ & $411-469$ & \\
\hline $\begin{array}{l}\text { Apnoea-hypopnoea index } \\
\text { events per } h\end{array}$ & $57.8 \pm 5.5$ & $52.4 \pm 7.2$ & 0.4 & $56.6 \pm 8.1$ & $52.0 \pm 8.4$ & 0.39 \\
\hline Median & 58.6 & 49.8 & & 58.7 & 50.4 & \\
\hline Interquartile range & $42.0-72.5$ & $39.3-61.3$ & & $42.0-71.5$ & $43.7-63.9$ & \\
\hline Apnoea-hypopnoea time \% & $40.0 \pm 5.8$ & $36.6 \pm 5.3$ & 0.24 & $33.1 \pm 5.5$ & $30.9 \pm 5.3$ & 0.57 \\
\hline Median & 36.9 & 36.4 & & 24.4 & 28.2 & \\
\hline Interquartile range & $26.1-55.2$ & $26.5-48.3$ & & $20.5-41.9$ & $25.1-40.6$ & \\
\hline Apnoea index events per $h$ & $31.2 \pm 7.2$ & $27.0 \pm 6.3$ & 0.44 & $27.1 \pm 8.5$ & $29.5 \pm 8.5$ & 0.44 \\
\hline Median & 30.3 & 29.6 & & 13.4 & 24 & \\
\hline Interquartile range & $10.4-50.4$ & $8.4-40.6$ & & $10.8-37.5$ & $14.8-37.3$ & \\
\hline Hypopnoea index events per $h$ & $26.6 \pm 4.5$ & $25.4 \pm 4.6$ & 0.57 & $29.5 \pm 4.0$ & $22.5 \pm 4.1$ & 0.11 \\
\hline Median & 25.2 & 21.3 & & 27.2 & 22.1 & \\
\hline Interquartile range & $15.1-33.9$ & $14.5-339.9$ & & $24.2-39.6$ & $11.6-33.0$ & \\
\hline $\mathrm{O}_{2}$ desaturation index & $56.8 \pm 5.4$ & $51.4 \pm 6.6$ & 0.44 & $55.0 \pm 7.9$ & $51.4 \pm 7.8$ & 0.44 \\
\hline Median & 59.0 & 47.0 & & 42.5 & 51.7 & \\
\hline Interquartile range & $40.5-70.8$ & $40.5-61.1$ & & $35.7-73.9$ & $40.2-61.5$ & \\
\hline Mean $S_{\mathrm{aO}_{2}} \%$ & $91.0 \pm 0.9$ & $91.8 \pm 0.8$ & 0.24 & $92.6 \pm 0.6$ & $92.9 \pm 0.4$ & 0.57 \\
\hline Median & 91.4 & 91.8 & & 92.9 & 93.3 & \\
\hline Interquartile range & $91.1-92.6$ & $90.3-93.2$ & & $92.0-93.9$ & $92.4-93.7$ & \\
\hline $\mathrm{S}_{\mathrm{aO}_{2}}<90 \%$ time $\%$ & $27.0 \pm 8.1$ & $20.6 \pm 5.4$ & 0.24 & $14.4 \pm 5.4$ & $10.5 \pm 3.6$ & 0.47 \\
\hline Median & 19.7 & 16.0 & & 6.7 & 9.7 & \\
\hline Interquartile range & $8.7-36.8$ & $6.5-35.5$ & & $4.1-16.3$ & $5.2-10.4$ & \\
\hline Snoring time \% & $24.9 \pm 7.0$ & $25.1 \pm 6.6$ & 0.54 & $36.5 \pm 6.9$ & $28.8 \pm 7.1$ & 0.44 \\
\hline Median & 18.9 & 23.2 & & 43.2 & 23.5 & \\
\hline Interquartile range & $5.3-45.8$ & $7.0-38.4$ & & $17.4-49.1$ & $11.5-38.4$ & \\
\hline Mean nocturnal HR bpm & $72.3 \pm 1.7$ & $68.4 \pm 2.0$ & 0.07 & $73.3 \pm 4.5$ & $73.0 \pm 4.2$ & 0.64 \\
\hline Median & 72.0 & 69.0 & & 73.0 & 73.5 & \\
\hline Interquartile range & $67.8-73.8$ & $63.0-71.5$ & & $63.8-83.0$ & $64.5-82.8$ & \\
\hline \multicolumn{7}{|c|}{$\begin{array}{l}\text { Data are presented as mean } \pm \mathrm{SE} \text { unless otherwise stated. } \mathrm{S}_{\mathrm{aO}_{2}} \text { : arterial oxyhaemoglobin saturation; } \\
\mathrm{HR} \text { : heart rate; bpm: beats per min; time in \%: proportion of recording time. A p-value }<0.002 \text { was } \\
\text { considered statistically significant. }\end{array}$} \\
\hline
\end{tabular}


$61.7 \pm 9.6 \cdot \mathrm{h}^{-1}$ in the intervention group. We point out that no patients showed aggravation of night-time polygraphy results with the collar and that one patient in the intervention group showed significant OSA improvement with the collar (AHI minus 67\%). This patient wished to keep the collar to treat her OSA when the 23 other recruited patients accepted CPAP therapy after the study.

Regarding the comparison of the standardised evolution indicators between the control and intervention groups, Cohen's $d$ values were on average $d=0.33$, a small effect size that indicates a low power analysis of the comparison. For a stronger power analysis with a large effect size $(d=0.8)$, calculations showed that 123 patients would have to be included in each group and parametric paired t-tests used for comparison.

Few authors assessed the effects of cervical collars in OSA. For instance, with a rigid item in 10 patients during the night-time for 1 month, Skinner et al. observed two participants treated effectively and two others partially in terms of AHI reduction [4]. Note that we studied severe OSA patients $\left(\mathrm{AHI}=56.6 \pm 8 \cdot 1 \cdot \mathrm{h}^{-1}\right)$ whereas patients had mild-to-moderate OSA $\left(\mathrm{AHI}=24 \pm 13 \cdot \mathrm{h}^{-1}\right)$ in the Skinner study. The rigid collar pictured in the Skinner article appears bulkier than our soft collar, the two supports looking like different devices even though their use has similar aims. In the literature on habitual indications for a cervical support, rigid and soft supports are compared and frequently opposed. Skinner used cephalometric radiographs and complex measurements to demonstrate that the rigid collar adjusted with a specific complex instrument to maintain the natural head position increased pharyngeal diameter. Nevertheless, questions arise as to what constitutes the natural head position: "what is it in a sleeping person? Is there any similarity between the natural head position determined in an awake status, even in the supine position, and the various and uncontrolled head/neck positions during sleep?" Skinner et al. also specified that their method of collar adjustment and morphometry was not associated with changes in polysomnographic outcome and therefore had no relationship with airway functional patency. In our study, optimisation of the support was simply based on a compromise between a good blockage of head/ neck/mandible movements and comfort/tolerance of the collar. With the correct model in terms of height and length, the patient was shown how to correctly tighten the collar to minimise cervical and head movements such as antero-posterior flexion/extension and backward motion of the mandible while remaining able to breathe normally, with no sensation of strangulation or difficulty in swallowing. It was what we termed a significant limitation of head motion. Our collar was directly applied and tightened around the neck whereas the neck remained free in the Skinner study, in which major inconveniences were related to the intrusive frame of the support. These elements explain how discomfort/intolerance criteria of the two devices differ. We esteem that the ways to adjust the collar during the device tests in Skinner's and our own studies finally led to the same results regarding pharyngeal patency. Indeed, in both studies all the patients had to set up and fasten their collar alone at home in the evening before going to bed and adjusting it with self-adhesive attachments, moreover, placed at the back of the neck. Those real-life conditions might have introduced an element of uncertainty in collar installation despite all efforts from the investigators to initially optimise collar adjustment.

More recently was published a series of five patients in whom a soft collar could be effective against mandible retrusion due to facial mask in CPAP ventilation [12]. Interestingly, authors suggested that a cervical support could act not only by mechanical restriction but also as a proprioceptive guide leading to spontaneous self-regulation of the head and cervical motion $[1,2]$.

Due to the absence of collar impact on severe OSA in the present study, in the case of a full RCT, design could include a midway analysis to see if the absence of collar effect would still be observed, permitting discussion of premature trial interruption.

In this small-scale short-term pilot study, and as an alternative to CPAP, a soft cervical collar was well tolerated and had no effect on pharyngeal functional patency, according to polygraphy data in patients with severe OSA. For conclusive results an RCT appeared feasible with 246 inclusions. Further study could also concern the effects of such a support in mild or moderate OSA, such as in patients ineligible for CPAP.

Philippe Bordier $\circledast^{1,2}$, Aurélia Lataste ${ }^{2}$, Sébastien Orazio $^{3}$, Jérémy Papin ${ }^{2}$, Frédéric Robert ${ }^{2}$ and Ghalia Bourenane ${ }^{2}$

${ }^{1}$ Haut-Leveque Cardiology Hospital, Pessac, France. ${ }^{2}$ Sud-Gironde Hospital Center, Langon, France.

${ }^{3}$ Bergonie Institute Unicancer, Bordeaux, France.

Correspondence: Philippe Bordier, Hôpital Cardiologique du Haut-Lévêque, Unité de Maladie Coronaire, Avenue de Magellan, 33604 Pessac cedex, France. E-mail: phibordier@aol.com

Received: 31 May 2020 | Accepted after revision: 27 Oct 2020 
Acknowledgements: Special thanks to Alan Metcalfe for his help in the present article.

Author contributions: All authors have seen and approved the manuscript.

Conflict of interest: None declared.

\section{References}

1 Miller CP, Bible JE, Jegede KA, et al. Soft and rigid collars provide similar restriction in cervical range of motion during fifteen activities of daily living. Spine 2010; 35: 1271-1278.

2 Whitcroft KL, Massouh L, Amirfeyz R, et al. A comparison of neck movement in the soft cervical collar and rigid cervical brace in healthy subjects. J Manipulative Physiol Ther 2011; 34: 119-122.

3 Walsh JH, Maddison KJ, Platt PR, et al. Influence of head extension, flexion, and rotation on collapsibility of the passive upper airway. Sleep 2008; 31: 1440-1447.

4 Skinner MA, Kingshott RN, Jones DR, et al. Lack of efficacy for a cervicomandibular support collar in the management of obstructive sleep apnea. Chest 2004; 125: 118-126.

$5 \quad$ Jordan AS, McSharry DG, Malhotra A. Adult obstructive sleep apnoea. Lancet 2014; 383: 736-747.

6 Sullivan CE, Issa FG, Berthon-Jones M, et al. Reversal of obstructive sleep apnoea by continuous positive airway pressure applied through the nares. Lancet 1981; 1: 862-865.

7 Doff $\mathrm{MH}$, Hoekema A, Wijkstra PJ, et al. Oral appliance versus continuous positive airway pressure in obstructive sleep apnea syndrome: a 2-year follow-up. Sleep 2013; 36: 1289-1296.

8 Berry RB, Brooks R, Gamaldo CE, et al. The AASM Manual for the Scoring of Sleep and Associated Events: Rules, Terminology and Technical Specifications, version 2.3. Darien, Illinois, American Academy of Sleep Medicine, 2016.

9 Sidak ZK. Rectangular confidence regions for the means of multivariate normal distributions. J Am Stat Assoc 1967; 62: 626-633.

10 Bordier P, Orazio S, Hofmann P, et al. Short- and long-term effects of nocturnal oxygen therapy on sleep apnea in chronic heart failure. Sleep Breath 2015; 19: 159-168.

11 Cohen J. Statistical power analysis. Curr Dir Psychol Sci 1992; 1: 98-101.

12 Prigent A, Grassion L, Guesdon S, et al. Efficacy of the addition of a cervical collar in the treatment of persistent obstructive apneas despite continuous positive airway pressure. J Clin Sleep Med 2017; 13: 1473-1476. 